\title{
Investigation of Vegetation Cover Change in Sudan by Using Modis Data
}

\author{
Yousif Elnour Yagoub1,2,3*, Zhongqin Li1 ${ }^{1}$ Omer Said Musa², Muhammad Naveed Anjum ${ }^{4}$, \\ Feiteng Wang1, Chunhai Xu' ${ }^{1}$, Zhang $\mathrm{Bo}^{3}$
}

\author{
${ }^{1}$ State Key Laboratory of Cryospheric Sciences/Tian Shan Glaciological Station, Northwest Institute of Eco-Environment and \\ Resources, CAS, Lanzhou, China \\ ${ }^{2}$ Department of Forest Protection and Conservation, Faculty of Forestry, University of Khartoum, Shambat, Sudan \\ ${ }^{3}$ College of Geography and Environmental Science, Northwest Normal University, Lanzhou, China \\ ${ }^{4}$ Division of Hydrology Water-Land Resources, Northwest Institute of Eco-Environment and Resources, CAS, Lanzhou, China \\ Email: *yousif@lzb.ac.cn, *yousifelnouryagoub@yahoo.com
}

How to cite this paper: Yagoub, Y.E., Li, Z.Q., Musa, O.S., Anjum, M.N., Wang, F.T., Xu, C.H. and Bo, Z. (2017) Investigation of Vegetation Cover Change in Sudan by Using Modis Data. Journal of Geographic Information System, 9, 279-292. https://doi.org/10.4236/jgis.2017.93017

Received: April 18, 2017

Accepted: June 6, 2017

Published: June 9, 2017

Copyright $\odot 2017$ by authors and Scientific Research Publishing Inc. This work is licensed under the Creative Commons Attribution-NonCommercial International License (CC BY-NC 4.0). http://creativecommons.org/licenses/by-nc/4.0/

\begin{abstract}
The aim of this research paper is to investigate the land cover changes in Sudan during the period 2001-2013 by using the MODIS data and to identify climatic factors influencing the land cover. SPSS v 17 software was used to investigate the correlation of climatic factors with vegetation cover; also ArcGIS v 10.2 software was used to analyze the NDVI data. The results indicate that the monthly average time scale, NDVI value curve distribution during the year, July to October as the center to both sides of decreasing vegetation cover in other months. In the spatial distribution of mean NDVI in Sudan, a high value was found in the southern part. On the other hand, a low value of vegetation cover was found in northern part. NDVI spaces mean presenting features values: autumn followed by summer then winter. By calculation of average annual and seasonal-NDVI values, it was deduced that the main vegetation cover type was increasing in winter and summer seasons at the rates of $0.014 / 10 \mathrm{a}$ and $0.008 / 10 \mathrm{a}$, respectively. While winter-NDVI was decreasing the rate of 0.001/10a and 0.026/10a in autumn and on the annual scale, respectively. Annual NDVI showed a significant degradation (area $=12705.7 \mathrm{~km}^{2}, 0.5 \%$ of total area) in the middle and eastern parts and significant improvement (area $=22485.4 \mathrm{~km}^{2}, 0.9 \%$ of the total area) in the southern part of the country due to the increase in precipitation and decrease in temperature. Mean summer and autumn-NDVI showed a significant difference $0.01 \%$ significance level with mean summer and autumn precipitation (correlation coefficients $=0.955$ and 0.953 , respectively). While there was a significantly negative relationship between mean summer and autumn-NDVI with mean summer and autumn temperature at $0.01 \%$ significance level (correlation coefficients $=-0.270$ and -0.820 , respectively).
\end{abstract}




\section{Keywords}

Land Cover Changes, Climate Factors, NDVI, Sudan

\section{Introduction}

Drought that started in 1968 and persisted very strongly throughout the 1970 s and 1980-1981 continued into 1982 which was the third driest year of the period 1968-1982, and also appeared to have received substantially less rainfall than the drought years of the 1940s [1]. Sudan is one of the most vulnerable countries to climate change and climate variability. This situation is aggravated by the interaction of multiple stresses occurring at various levels, such as endemic poverty; institutional weaknesses; limited access to capital, including markets, infrastructure and technology, ecosystem degradation, complex disasters and conflicts. These, in turn, have weakened people's adaptive capacity, increasing their vulnerability to projected climate change. In recent times, human activities have caused, and are continuing to cause great changes to the composition of the atmosphere. The major concern of both scientific and public communities is the enhanced greenhouse effect caused by anthropogenic activities. In 1977, 57 million people in dry lands were suffering the direct effects of land degradation to the extent where it no longer produced enough food to sustain them. By 1984, their number had risen to 135 million [2]. The Sahara desert has been described as encroaching southwards at an increasing rate. This desertification phenomenon has been considered to be mainly human-induced. Sudan is one of the driest but also the most variable countries in Africa in terms of rainfall. Extreme years (either good or bad) are more common than average years [3]. Rural water supply in semi-arid Sudan is closely dependent upon annual rainfall. In semiarid Sudan, water availability is the primary constraint upon human habitation and activity. Large areas of central Sudan are characterized by an inadequate supply of water to meet even the basic daily requirements of man and livestock [4]. During the last decade, the African regions and countries have been the subject of a number of assessments and interpretations of temperature trends. Over eastern Africa, nighttime warming and daytime cooling in the northern part of the region and cooling during both times of the day in the Mozambique Channel region were evident [5]. The devastating Sahelian desiccation over the last generation of the 20th century has motivated many scientists to identify the changes in drought conditions in Sudan [6] [7], perhaps due to the diversified vegetation and climatic features of the country. Several studies showed that the Sudan is suffering from degradation of its land resources through overgrazing, range fires, deforestation, inappropriate agricultural practices and the highly variable rainfall and recurrent droughts [8]. As reported by [9] that the recurrence last drought periods in Sudan for the most times was moderate except the fact that in 1984, 1991, and 2000 most of Sudan and South Sudan has witnessed extreme and severe drought periods. There is a wide seasonal and spatial variability 
in drought intensity, as some areas became drier in summer and wetter in autumn and winter.

The objectives of this research are to investigate the land cover change in Sudan during the period 2001-2013 by using the MODIS data, in addition, to investigate climatic factors affecting the land cover as recommended by [10], for further research on the use of remote sensing in monitoring LULC changes in Sudan. Particularly these studies not only improve our understanding about LULC changes but also its implications in management and conservation efforts. LULC changes in the eastern part of Sudan by using multi-temporal Landsat data showed that a significant extensive change of natural vegetation patterns has occurred during 1987-2013 [11].

All records of monthly precipitation and temperature on a spatial resolution of $0.5 \times 0.5$ degree grids containing 845 stations were downloaded from Climatic Research Unit,

https://crudata.uea.ac.uk/cru/data/hrg/cru_ts_3.22/cruts.1406251334.v3.22/.

ArcGIS v 10.2 software was used for analyzing and mapping the vegetation cover. SPSS software was used to investigate the correlation of climate factor with vegetation cover.

\section{Material and Methods}

\subsection{Study Area}

Figure 1 showed the map of Sudan. The country is located in the northeastern part of Africa. The area of the Sudan is $2,501,010 \mathrm{~km}^{2}$ (including both Sudan and South-Sudan), extending from latitude of $2^{\circ} 40^{\prime}-22^{\circ} 30^{\prime} \mathrm{N}$ and from longitude $21^{\circ} 50^{\prime}-38^{\circ} 50^{\prime} \mathrm{E}$, altitude varies between 40 and $870 \mathrm{~m}$. According to [12] during the hot summer, the maximum temperature exceeds $40^{\circ} \mathrm{C}$. As many other Sahelian African countries, Sudan is a drought prone area. Findings indicate that drought has become more recurrent in recent decades, of which those of the early to mid-1970s, mid-1980s; early 1990s and early 2000s can be noted as common drought years and were among the driest 10 years in the central region of Sudan [13]. Sudan expanded its agricultural production mainly through an increase in rain-fed cropland, 42 percent under large-scale mechanized agriculture and the remainder under small-scale traditional cultivation, and kept its per capita total crop area at about 0.49 hectares which is quite high by regional and global standards [14].

\subsection{Normalized Difference Vegetation Index (NDVI)}

The MODIS data has a 16-day temporal and $250 \mathrm{~m}$ spatial resolution (MOD13Q1, collection 5). MODIS data for the period of 2001-2013 is obtained from ftp://ladsweb.nascom.nasa.gov/allData/5/MOD13Q1. This data is maintained by the NASA in Land Processes Distributed Active Archive Center (LP DAAC) at the USGS/Earth Resources Observation and Science (EROS) Centre. Original MODIS_NDVI is scene in (h20v06, 07 and 08, and h21v06, 07 and 08) for Sudan. The website: http://phenology.cr.usgs.gov/ndvi_foundation.php is 


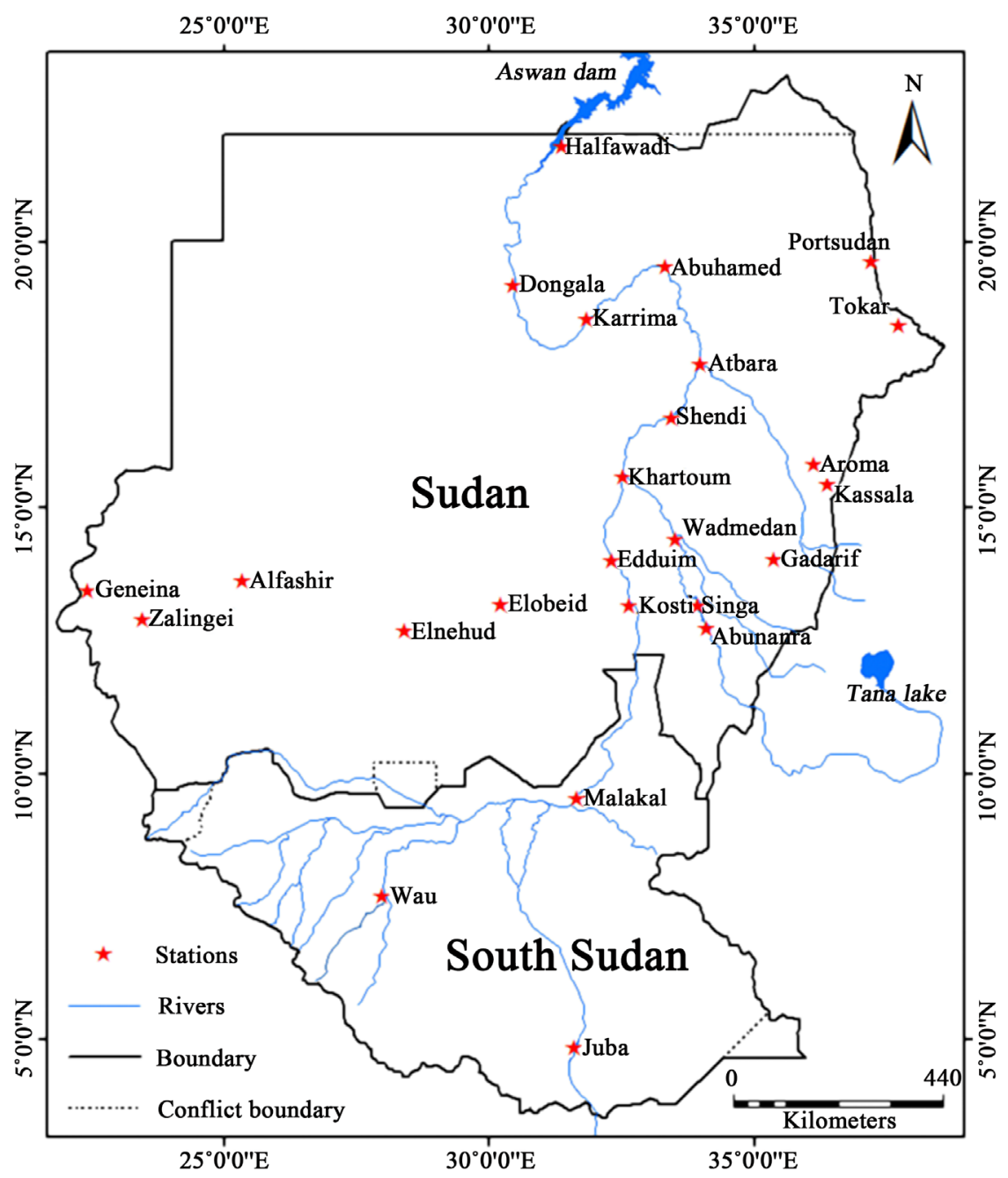

Figure 1. The distribution of meteorological stations in study areas.

used to download the NDVI value. A vegetation index is an indicator that describes the greenness, the relative density and health of vegetation for each picture element (pixel) in a satellite image. Although there are several vegetation indices, one of the most widely used is the Normalized Difference Vegetation Index (NDVI), NDVI values range from 1.0 to -1.0 .

\subsection{Linear Trend (Slope)}

Linear regression trend analysis by using ArcGIS v 10.2 software can simulate trends in each grid [15]; and can reflect different periods of vegetation cover spatial trends characteristics. Formula:

$$
\theta \text { Slope }=\frac{n \times \sum_{i=1}^{n} i \times N D V I_{i}-\sum_{i=1}^{n} i \sum_{i=1}^{n} N D V I_{i}}{n \times \sum_{i=1}^{n} i^{2}-\left(\sum_{i=1}^{n} i\right)^{2}}
$$

where $i$ is the annual number; $\mathrm{n}$ is monitoring period (the cumulative number of years); NDVI as NDVI mean value of the $i$ year; slope is each pixel NDVI trends of the slope, if $\theta$ Slope $>0$, indicating that the pixel NDVI value in $n$ years is 
increasing, otherwise it is decreasing. This study is categorized into a significant increase, slight increase, essentially the same, slightly reduced and a significant reduction, and the statistics of the study area in 2001-2013 vegetation changes and the percentage of each class area.

\subsection{Correlation}

Correlation between geographical elements, it is possible to explain the closeness of the relationship between geographic features, and closely related to the degree of mutual determination between geographical elements, mainly through the correlation coefficient calculation. In this research, study of NDVI and average annual temperature and annual precipitation by-pixel spatial correlation, the correlation coefficient used to reflect the sequence of climatic factors and NDVI degree of correlation, the correlation coefficient value is between -1and 1. Formula:

$$
r_{x y}=\frac{\sum_{i=1}^{n}\left(x_{i}-\bar{x}\right)\left(y_{i}-\bar{y}\right)}{\sqrt{\sum_{i=1}^{n}\left(x_{i}-\bar{x}\right)^{2} \sum_{i=1}^{n}\left(y_{i}-\bar{y}\right)^{2}}}
$$

where: $n$ is the number of time series, $x$ and $y$ are two elements of the correlation, and represent the average of the two elements of the sample values, and finally delineated thresholds based on the number of data, the results of the correlation level of significant.

\section{Result and Discussions}

Sudan has complex and diverse climate types, uneven distribution of water resources and serious water shortages in the northern part, harsh natural conditions and a high frequency of drought. A drought is one of the most important natural disasters in Sudan. Drought disasters in Sudan agricultural production especially for relatively large impact not only affect the stability and security of food production, but also is a one of the main factors restricting the development of Sudan economy.

\subsection{Vegetation Cover of Monthly Time Scale}

Figure 2 showed the vegetation variation in Sudan, on monthly average time scale, NDVI value showed a peak curve distribution in the year. July to October as the center to both sides of decreasing vegetation cover in descending order of the year, which corresponds to the average monthly vegetation NDVI values were: $0.2,0.19,0.19,0.2,0.21,0.26,0.32,0.36,0.36,0.32,0.26$ and 0.22 for the months from January to December, respectively. Overall, in the growing season (July to October), the highest vegetation cover was recorded in autumn.

\subsection{Spatial Distribution of Vegetation Cover}

The spatial distribution of mean NDVI in Sudan, Figure 3 showed that the mean annual and seasonal-NDVI, as a whole, have high values in the southern part. 


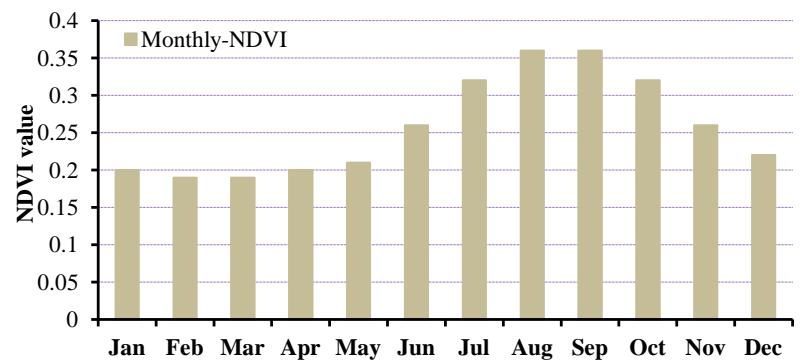

Figure 2. The distribution of the mean monthly-NDVI in Sudan during 2001-2013.
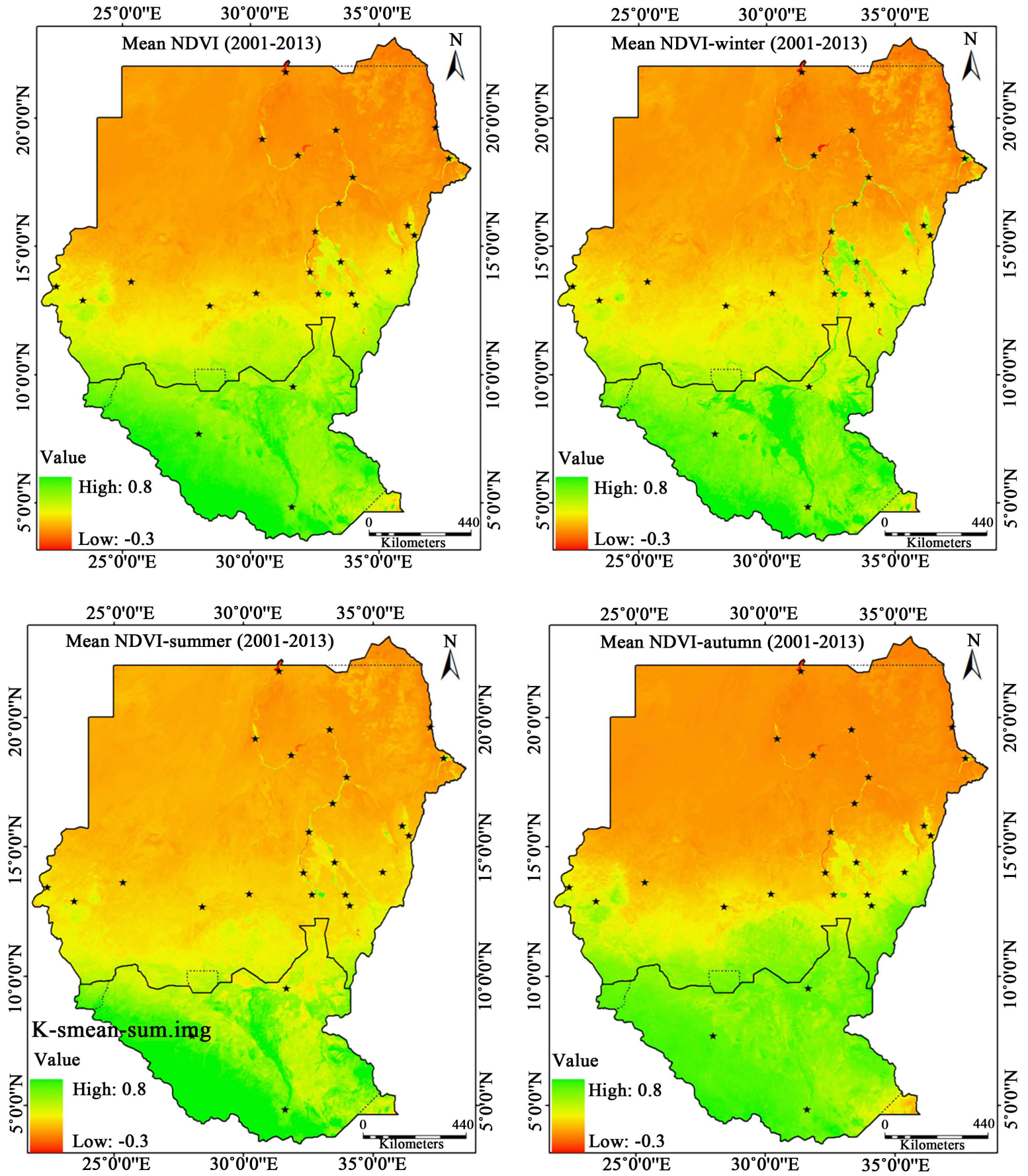

Figure 3. Spatial distribution of mean annual and seasonal-NDVI in Sudan during 2001-2013. 
The vegetation cover is high in the south of Sudan due to humid climatic zone near the equator; the vegetation cover is widely distributed in woodland, grasslands and crops, vegetation in forests, and grasslands with a high NDVI value. The Northern part has a low value of vegetation cover; NDVI is negative in areas covered by sand, rock and desert due to their location in the biggest desert in the world. Figure 4 showed the distribution of the mean monthly NDVI in Sudan
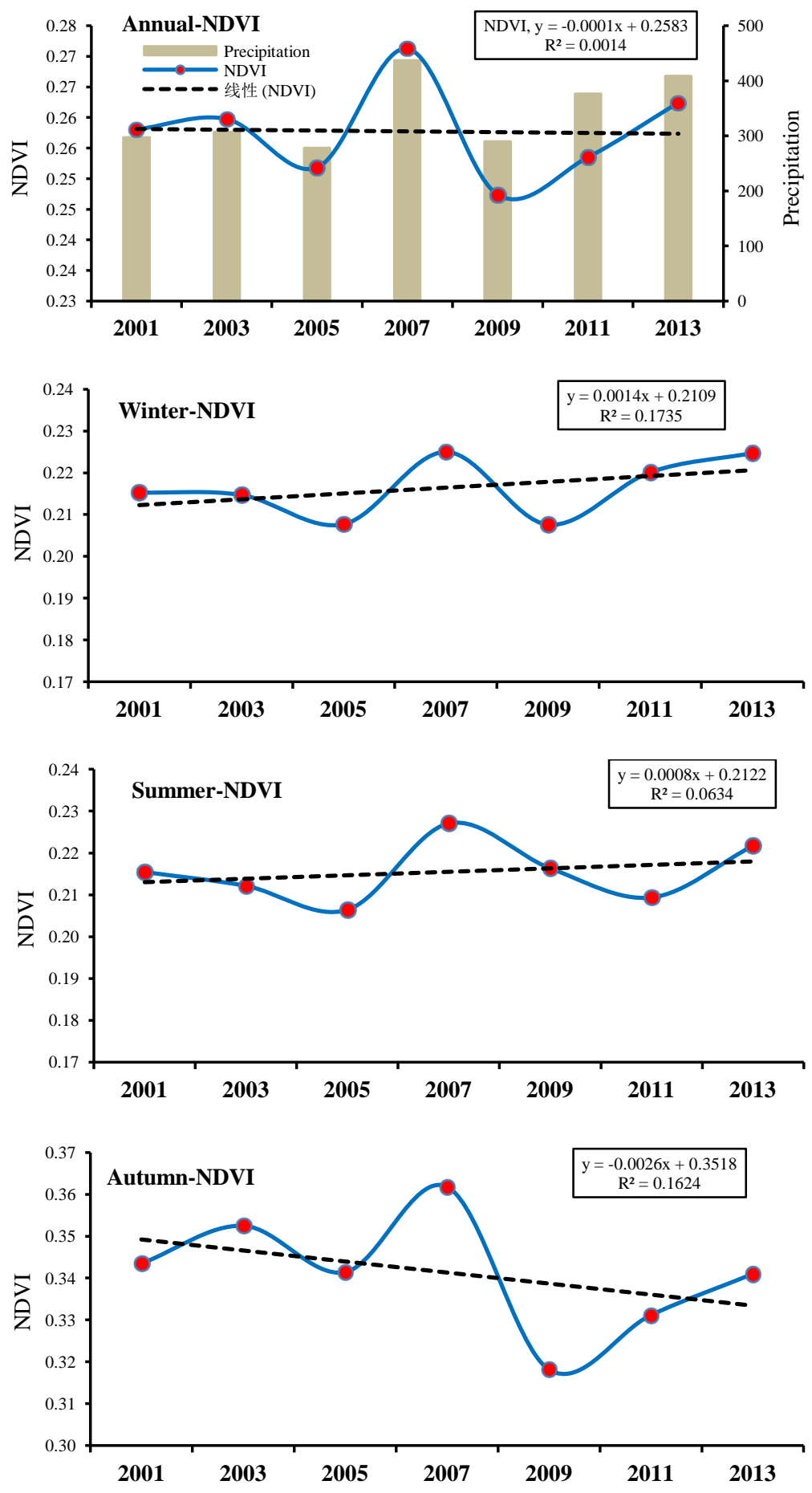

Figure 4. Trend of different vegetation types, annual and seasonal-NDVI change in Sudan 2001-2013. 
during 2001-2013 (showing different trends in autumn follow by summer then winter). The NDVI has different value due to seasonal differences in the degree of green crops and woodland, grassland due to seasonal changes in climatic factors. By calculating the average annual and seasonal-NDVI value, it was found that the main vegetation cover type has an upward trend at a rate of $0.014 / 10 \mathrm{a}$ and $0.008 / 10 \mathrm{a}$, for winter and summer, respectively. While NDVI has a downward trend at a rate of 0.001/10a and 0.026/10a for annual and autumn, respectively.

\subsection{Spatial Variation of Vegetation Cover}

\subsubsection{Annual}

Based on principle slope (calculated by linear regression) value (between -1 and 1) of mean annual-NDVI in Sudan during 2001 - 2013, the land was reclassified from low to high values into seven categories: significant degradation, moderate degradation, mild degradation, no change, mild improvement, moderate improvement and significant improvement. Figure 5 and Table 1 showed the spatial variation of vegetation cover: significant degradation area is $12705.7 \mathrm{~km}^{2}$ (accounts to $0.5 \%$ of the total area) and most of this area is located in the middle and eastern part; moderate degradation area is $28343.4 \mathrm{~km}^{2}$ (accounts to $1.1 \%$ of the total area); mild degradation area is $94,550.6 \mathrm{~km}^{2}$ (accounts to $3.8 \%$ of the total area); no change area is $2,118,701.5 \mathrm{~km}^{2}$ (accounts to $84.7 \%$ of the total area); mild improvement area is $150,225.9 \mathrm{~km}^{2}$ (accounts to $6.0 \%$ of the total area); moderate improvement area is $73,997.4 \mathrm{~km}^{2}$ (accounts to $3.0 \%$ of the total area) and significant improvement area is $22,485.4 \mathrm{~km}^{2}$ (accounts to $0.9 \%$ of the total area).

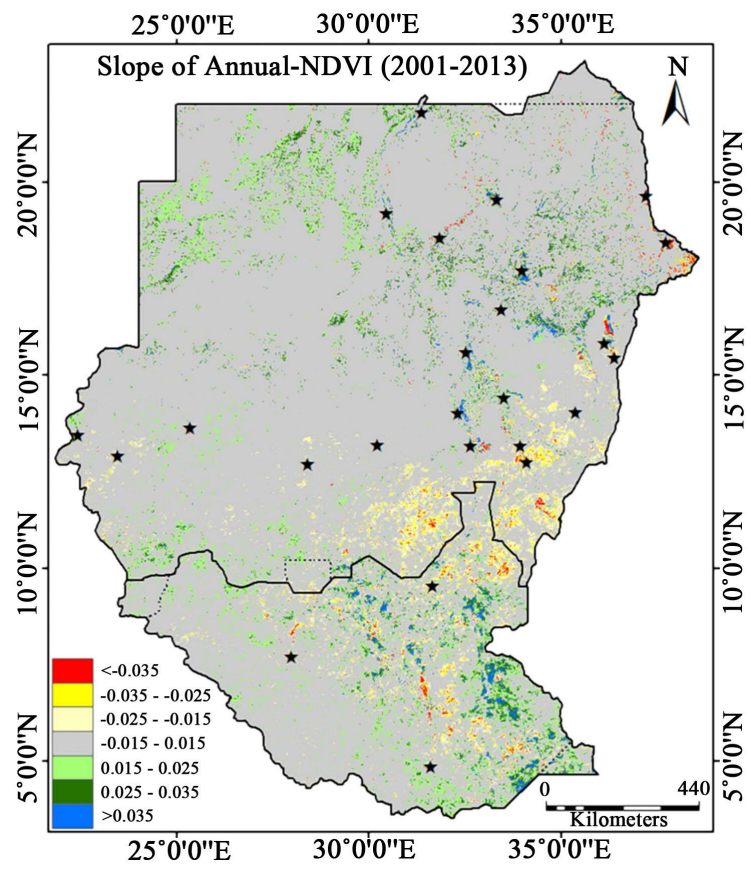

Figure 5. Spatial-temporal change characteristic of mean annual-NDVI based on the slope in Sudan during 2001-2013. 
Table 1. Statistical result of trend in mean annual-NDVI change simulated in Sudan during 2001-2013.

\begin{tabular}{ccccc}
\hline & \multirow{2}{*}{ Category } & $\theta_{\text {Slope }}$ range & \multicolumn{2}{c}{ Mean NDVI } \\
\cline { 4 - 5 } & & & Area Km & \% of total area \\
\hline 1 & Significant degradation & $\theta<-0.035$ & 12705.7 & 0.5 \\
2 & Moderate degradation & $-0.035<\theta>-0.025$ & 28343.4 & 1.1 \\
3 & Mild degradation & $-0.025<\theta>-0.015$ & 94550.6 & 3.8 \\
4 & No change & $-0.015<\theta>0.015$ & 2118701.5 & 84.7 \\
5 & Mild improvement & $0.015<\theta>0.025$ & 150225.9 & 6.0 \\
6 & Moderate improvement & $0.025<\theta>0.035$ & 73997.4 & 3.0 \\
7 & Significant improvement & $\theta>0.03$ & 22485.4 & 0.9 \\
& Total & & 2501010 & 100 \\
\hline
\end{tabular}

\subsubsection{Seasonal}

The mean vegetation cover in Sudan during 2001-2013 is calculated by using a linear regression analysis. Before the seasonal analysis of vegetation, the reclassified NDVI was further divided into seven categories (from low to high values): significant degradation, moderate degradation, mild degradation, no change, mild improvement, moderate improvement and significant improvement. Figure 6 and Table 2 showed Sudan mean seasonal-NDVI. The spatial variation of significant degradation is $0.9 \%, 0.9 \%$, and $5.1 \%$ of the total area in winter, summer and autumn, respectively. The high change of degradation in autumn is locating in the middle-eastern part of Sudan due to the decrease in precipitation and increase in temperature. While, the significant improvement is $2.2 \%, 3.3 \%$ and $2.0 \%$ of the total area in winter, summer and autumn, respectively. The high improvement is located in the southern part of Sudan due to the increase in precipitation and decrease in temperature. No change is $80.8 \%, 80.5 \%$ and $71.3 \%$ of the total area in winter, summer and autumn, respectively.

\subsection{Relationship between Vegetation Cover and Climatic Factors}

The correlation coefficients between NDVI and spatial variation of climatic factors in Sudan during 2001-2013 are calculated by using SPSS software. The spatial distributions of trends in precipitation and temperature are estimated by interpolating seasonal precipitation and temperature data. Figure 7 showed the presence of significant differences in seasonal precipitation and temperature trends. Spatial characteristics of seasonal temperature showed the variation in all northern parts of Sudan, mainly warming as the main feature has significant increasing trend, while seasonal precipitation showed decreasing trend in most of the northern parts of Sudan. Precipitation has a high increasing trend in southern part of Sudan. Table 3 showed that there is a significant positive relationship between mean winter-NDVI and mean winter precipitation at the $0.01 \%$ significance level (correlation coefficients $0.735^{* *}$ with p-value 0.00 ), while there is a significant positive relationship between winter-NDVI and mean winter tem- 
Table 2. Statistical result of trend of mean seasonal-NDVI change simulated in Sudan during 2001-2013.

\begin{tabular}{|c|c|c|c|c|c|c|c|c|}
\hline & \multirow{2}{*}{ Category } & \multirow{2}{*}{$\theta_{\text {Slope }}$ range } & \multicolumn{2}{|l|}{ Winter } & \multicolumn{2}{|c|}{ Summer } & \multicolumn{2}{|c|}{ Autumn } \\
\hline & & & Area $\mathrm{Km}^{2}$ & $\%$ & Area $\mathrm{Km}^{2}$ & $\%$ & Area $\mathrm{Km}^{2}$ & $\%$ \\
\hline 1 & $\begin{array}{l}\text { Significant } \\
\text { degradation }\end{array}$ & $\theta<-0.035$ & $21,307.1$ & 0.9 & 23439.6 & 0.9 & 128506.4 & 5.1 \\
\hline 2 & $\begin{array}{c}\text { Moderate } \\
\text { degradation }\end{array}$ & $-0.035<\theta>-0.025$ & $24,978.6$ & 1.0 & 34998.9 & 1.4 & 112684.1 & 4.5 \\
\hline 3 & $\begin{array}{c}\text { Mild } \\
\text { degradation }\end{array}$ & $-0.025<\theta>-0.015$ & $58,275.7$ & 2.3 & 72830.1 & 2.9 & 192501.9 & 7.7 \\
\hline 4 & No change & $-0.015<\theta>0.015$ & $2,020,584.8$ & 80.8 & 2014143.7 & 80.5 & 1782067.7 & 71.3 \\
\hline 5 & $\begin{array}{c}\text { Mild } \\
\text { improvement }\end{array}$ & $0.015<\theta>0.025$ & $210,813.6$ & 8.4 & 144869.6 & 5.8 & 134926.4 & 5.4 \\
\hline 6 & $\begin{array}{c}\text { Moderate } \\
\text { improvement }\end{array}$ & $0.025<\theta>0.035$ & $110,011.8$ & 4.4 & 128752.2 & 5.1 & 100675.8 & 4.0 \\
\hline 7 & $\begin{array}{c}\text { Significant } \\
\text { improvement }\end{array}$ & $\theta>0.03$ & $55,038.6$ & 2.2 & 81975.8 & 3.3 & 49647.8 & 2.0 \\
\hline & Total & & $2,501,010$ & 100 & 2501010 & 100 & 2501010 & 100 \\
\hline
\end{tabular}

Table 3. Correlation coefficients of NDVI with climate data using SPSS software in Sudan during 2001-2013.

\begin{tabular}{cccc}
\hline & Correlation & Pearson correlation & P value, Sig. (2-tailed) \\
\hline 1 & Winter-NDVI with precipitation & $0.735^{* *}$ & 0.000 \\
2 & Winter-NDVI with temperature & $0.739^{* *}$ & 0.000 \\
3 & Summer-NDVI with precipitation & $0.955^{* *}$ & 0.000 \\
4 & Summer-NDVI with temperature & $-0.270^{* *}$ & 0.000 \\
5 & Autumn-NDVI with precipitation & $0.953^{* *}$ & 0.000 \\
6 & Autumn-NDVI with temperature & $-0.820^{* *}$ & 0.000 \\
7 & Mean-NDVI with precipitation & $0.963^{* *}$ & 0.000 \\
8 & Mean-NDVI with temperature & $0.079^{*}$ & 0.020 \\
\hline
\end{tabular}

${ }^{*}$ Correlation is significant at the 0.01 level (2-tailed); ${ }^{\star}$ Correlation is significant at the 0.05 level (2-tailed).

perature at the $0.01 \%$ significance level (correlation coefficients $0.739^{* *}$ with $\mathrm{P}$ value 0.00). Mean summer-NDVI showed a high significant difference with mean summer precipitation at $0.01 \%$ significance level (correlation coefficients $0.955^{\star *}$ with $\mathrm{P}$ value 0.00 ), while there is a significant negative relationship between mean summer-NDVI and mean summer temperature at $0.01 \%$ significance level (correlation coefficients $-0.270^{\star *}$ with $\mathrm{P}$ value 0.00 ). There is a high significant positive relationship between mean autumn-NDVI with mean autumn precipitation at the $0.01 \%$ significance level (correlation coefficients $0.953^{* *}$ with $\mathrm{p}$-value 0.00 ), while there is a high significant difference between autumn-NDVI and mean autumn temperature (correlation coefficients $-0.820^{\star *}$ with $P$ value 0.00$)$. 

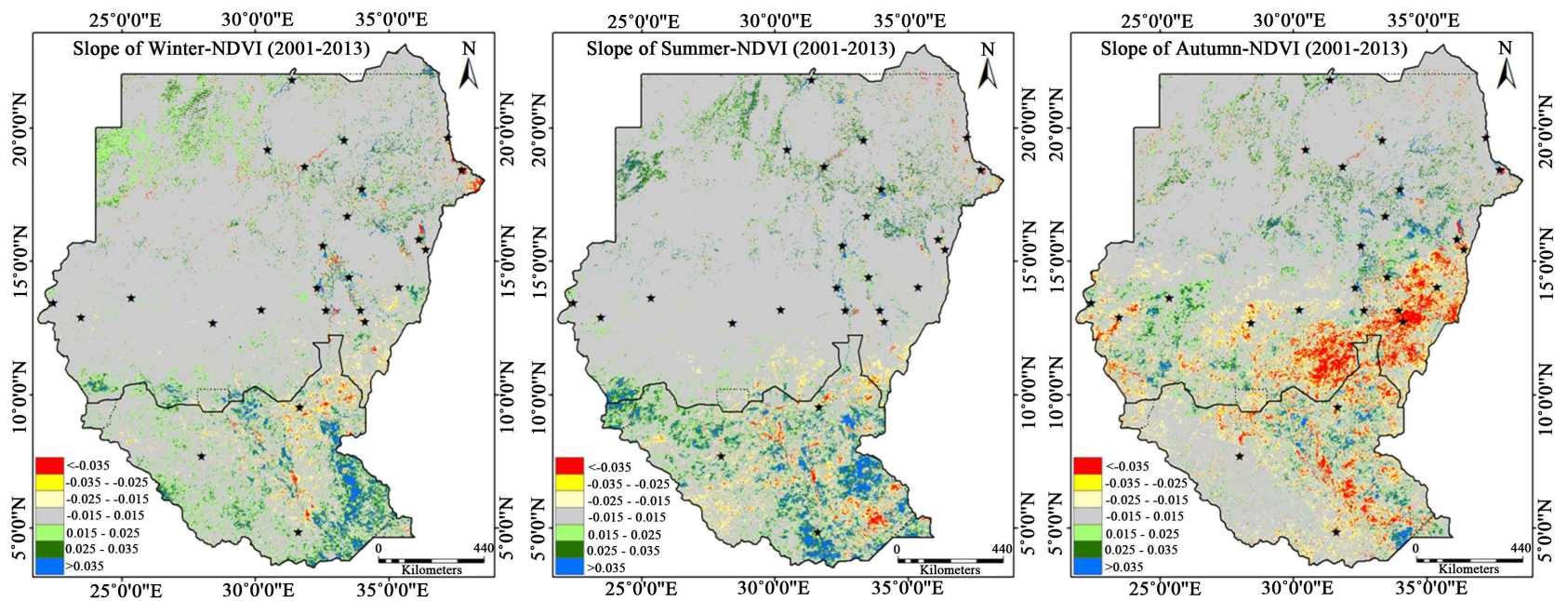

Figure 6. Spatial-temporal change characteristic of mean seasonal-NDVI based on the Slope in Sudan during 2001-2013.
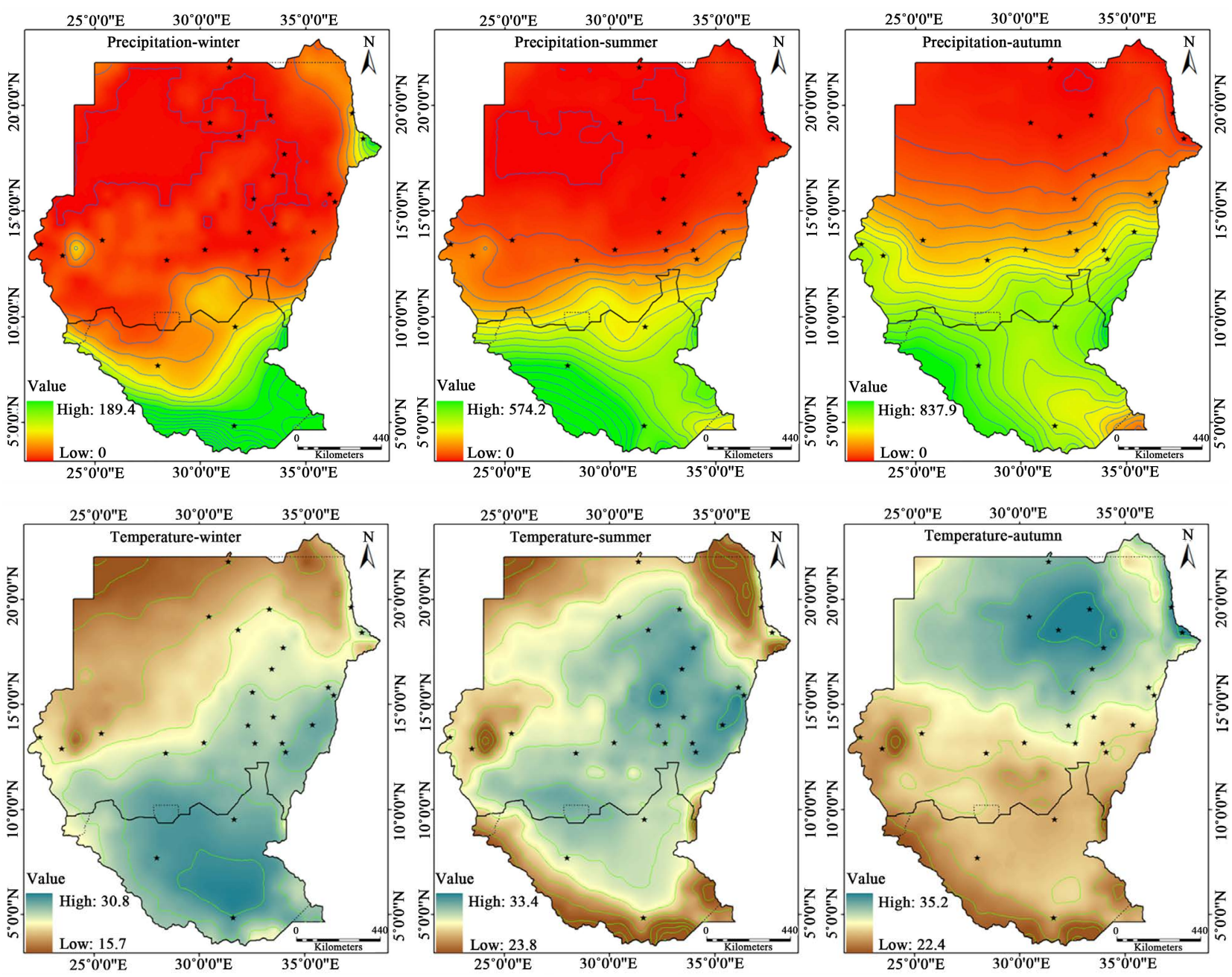

Figure 7. Spatial and temporal distribution of the mean seasonal trend of temperature and precipitation in Sudan during 2001-2013.

\subsection{Correlation of NDVI with Climatic Factors}

In order to find the relationship between high and low vegetation cover and cli- 
matic factors in Sudan, the mean annual precipitation and temperature data of 845 sites in recent 13 years was used. Using correlation method, grid related calculations are made in ArcGIS v 10.2 software, as shown in Figure 8. Table 3 showed that there is a high significant positive relationship between mean annual-NDVI and mean annual precipitation at the $0.01 \%$ significance level (correlation coefficient $0.963^{* *}$ with $p$-value 0.00 ), there is a significant positive relationship between the mean annual-NDVI and mean annual temperature at the $0.05 \%$ significance level (correlation coefficient $0.079^{\star}$ with $P$ value 0.02 ). To test the relationship of vegetation cover with annual precipitation and temperature, eight grades according to the principle of division of significance test at different threshold points were developed. Table 4 showed the statistics of the correlation

Table 4. The statistics of correlation coefficient between mean annual-NDVI and climate data factors in Sudan during 2001-2013.

\begin{tabular}{lcccccc}
\hline & \multirow{2}{*}{ Category } & Correlation & \multicolumn{2}{c}{ Precipitation } & \multicolumn{2}{c}{ Temperature } \\
\cline { 6 - 7 } & range & Area $\mathrm{Km}^{2}$ & $\%$ & Area $\mathrm{Km}^{2}$ & $\%$ \\
\hline 1 & A significant negative correlation & $<-0.03$ & 1724.7 & 0.1 & 6092.4 & 0.2 \\
2 & High negative correlation & $-0.03--0.02$ & 2811.9 & 0.1 & $13,776.8$ & 0.6 \\
3 & Moderate negative correlation & $-0.02--0.01$ & $20,583.4$ & 0.8 & $119,858.2$ & 4.8 \\
4 & Low negative correlation & $-0.01-0.00$ & $469,668.1$ & 18.8 & $1,203,204.6$ & 48.1 \\
5 & Low positive correlation & $0.00-0.01$ & $1,733,614.2$ & 69.3 & $1,102,266.6$ & 44.1 \\
6 & Moderate positive correlation & $0.01-0.02$ & $240,514.2$ & 9.6 & $45,983.9$ & 1.8 \\
7 & Highly correlated & $0.02-0.03$ & $22,945.4$ & 0.9 & 6061.8 & 0.2 \\
8 & A significant positive correlation & $>0.03$ & 9148.2 & 0.4 & 3765.7 & 0.2 \\
& Total & & $2,501,010$ & 100 & $2,501,010$ & 100
\end{tabular}
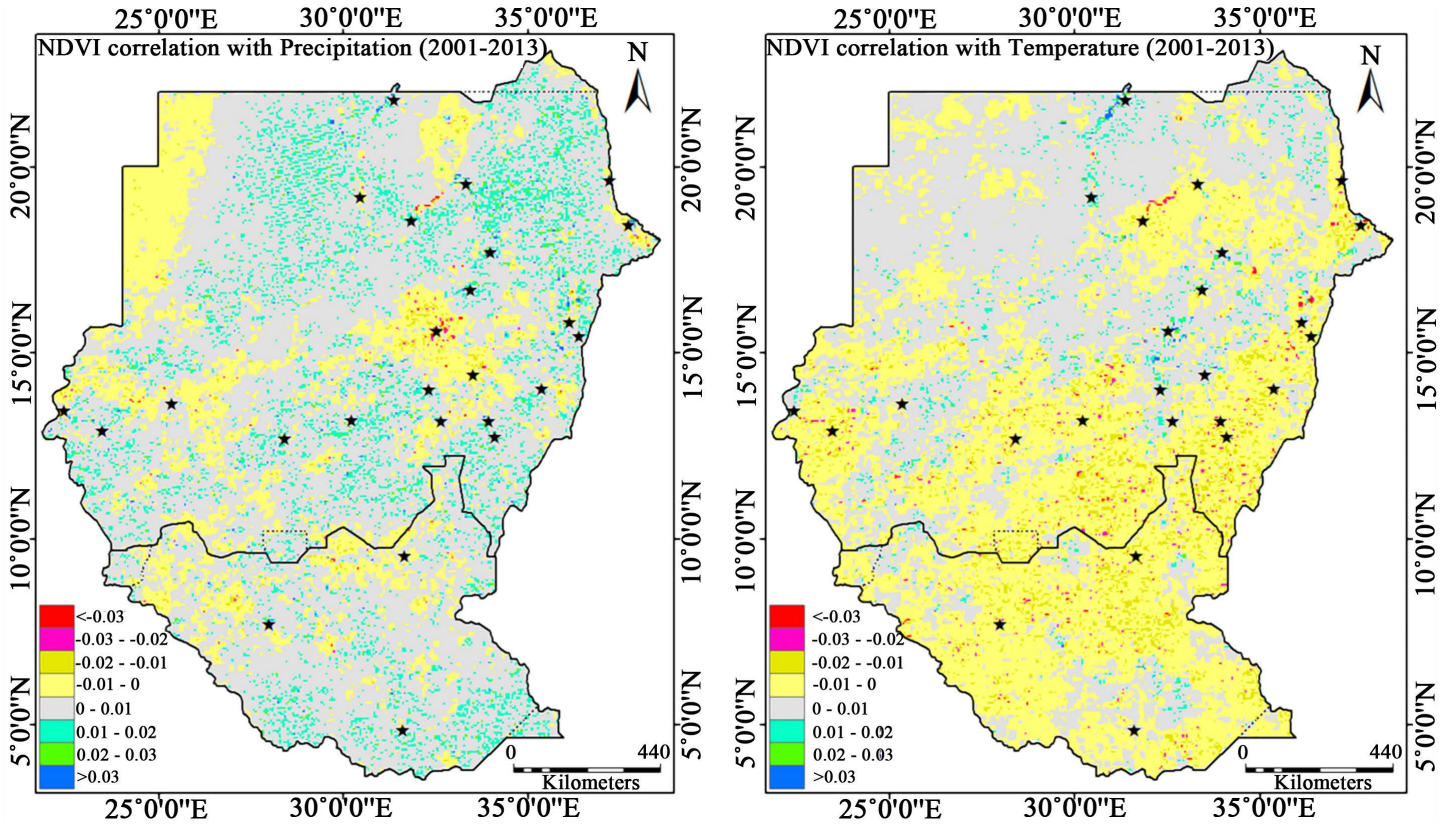

Figure 8. Correlation between mean annual-NDVI and climate factors in Sudan during 2001-2013. 
coefficient between mean annual-NDVI and climate data factor in Sudan during 2001-2013. The correlation coefficient between mean annual-NDVI and precipitation is a significant negative correlation, high negative correlation, moderate negative correlation and low negative correlation: $0.1,0.1,0.8$, and $18.8 \%$ of the total area, respectively. While low positive correlation, moderate positive correlation, high positive correlation and significant positive correlation is: $69.3 \%$, $9.6 \%, 0.9 \%$ and $0.4 \%$ of the total area, respectively. The correlation coefficients between mean annual-NDVI and temperature are significantly negative, high negative, moderate negative and low negative: $0.2 \%, 0.6 \%, 4.8 \%$ and $48.1 \%$ of the total area, respectively. While low positive correlation, moderate positive correlation, highly positive correlation and significant positive correlation are: $44.1 \%$, $1.8 \%, 0.2 \%$ and $0.2 \%$ of the total area, respectively.

\section{Conclusion}

Sudan is highly vulnerable to climate change and climate variability. Most drought studies focus on quantifying drought at the regional or global scale. The declination of grassland and palatable forbs resulted in the appearance of invader grasses that are unpalatable to livestock and can lead to livestock death and emergency slaughter which can result in economic losses and affect the livestock herders. This research showed successfully contribution of MODIS NDVI $250 \mathrm{~m}$ for the detection of the vegetation cover distribution in Sudan. Climatic factors have high effects on land cover. In spatial scale distribution of mean NDVI in Sudan, it is deduced that a high value of vegetation cover is in the southern part and a low value of that in northern part. Precipitation and temperature are the main factors which influence the change of vegetation cover and the impact is not same in different areas. The changes of vegetation cover were primarily influenced by temperature followed by precipitation. This information is of high value for setting up adaptation and mitigation strategies related to forest and natural resources.

\section{Acknowledgments}

The present research was supported by the National Natural Science Foundation of China (Grant no. 41471058 and 41641003), the NSFC project (grant number: 91425303), and the SKLCS funding (SKLCS-ZZ-2017).

\section{References}

[1] Peter, J.L. (1983) Sub-Saharan Rainfall Update for 1982: Continued Drought. Journal of Climatology, 3, 419-422.

http://onlinelibrary.wiley.com/doi/10.1002/joc.3370030410/full

[2] UNEP (1992) World Atlas of Desertification. Edward Arnold, Sevenoaks, 68 p.

[3] Zakieldeen, S.A. (2007) Vulnerability in Sudan. Tiempo Bulletin 62. Online bulletin at: http://www.tiempocyberclimate.org

[4] El Sammani, M. (1978) Gaps in the Water Provision Map of the Sudan. Sudan Notes and Records, 59, 97-106.

[5] King'uyu, S.M., Ogallo, L.A. and Anyamba, E.K. (2000) Recent Trends of Minimum 
and Maximum Surface Temperatures over Eastern Africa. Journal of Climate, 13, 2876-2886. https://doi.org/10.1175/1520-0442(2000)013<2876:RTOMAM>2.0.CO;2

[6] Eldredge, E. Khalil, S.E., Nicholds, N., Abdalla, A.A. and Rydjeski, D. (1988) Changing Rainfall Patterns in Western Sudan. Journal of climatology, 8, 45-53. http://onlinelibrary.wiley.com/doi/10.1002/joc.3370080105/full

[7] Walsh, R.P.D., Hulme, M. and Campbell, M.D. (1988) Recent Rainfall Changes and Their Impact on Hydrology and Water Supply in the Semi-Arid Zone of the Sudan, The Geographical Journal, 154, 181-198. https://doi.org/10.2307/633845

[8] Ayoub, A.T., (1998) Extent, Severity and Causative Factors of Land Degradation in the Sudan. Journal of Arid Environments, 38, 397-409. http://www.sciencedirect.com/science/article/pii/S0140196397903463

[9] Yagoub, Y.E., Li, Z., Musa, O.S., Wang, F., Anjum, .M.N., Bo, Z. and Ding-min, J. (2017) Detection Of Drought Pattern in Sudan Using Standardized Precipitation-Evapotranspiration Index (SPEI). International Journal of Recent Advances in Multidisciplinary Research, 4, 2546-2554.

http://www.ijramr.com/sites/default/files/issues-pdf/1348.pdf

[10] Yagoub, Y.E., Bo, Z., Ding-min, J., Jahelnabi, A.E. and Fadoul, S.M. (2015) Land Use and Land Cover Change in Northeast Gadarif State: Case of El Rawashda Forest, Sudan. Journal of Geographic Information System, 7, 140-157. https://doi.org/10.4236/jgis.2015.72013

[11] Yagoub, Y.E., Musa, O.S., Siddig, A.A., Bo, Z., Li, Z. and Wang, F. (2017) Assessing the Impacts of Land Use Changes on Vegetation Cover in Eastern Sudan. International Journal of Research in Agricultural Sciences, 4, 70-75.

https://ijras.org/administrator/components/com_jresearch/files/publications/IJRAS 505_FINAL.pdf

[12] UNESCO (1977) United Nations Educational, Scientific and Cultural Organization. Map of the World Distribution of Arid Regions. MAB Technical Notes 7, Paris.

[13] Elagib, N.A. (2009) Assessment of Drought across Central Sudan Using UNEP Dryness Ratio. Hydrology Research, 40, 481-494.

https://doi.org/10.2166/nh.2009.016

[14] Ministry of Environment and Tourism (1996) Towards a National Plan for Environmental Action in the Sudan (in Arabic). Miniistry of Environment and Tourism, Khartoum.

[15] Stow, D., Petersen, A. and Hope, A. (2007) Greenness Trends of Arctic Tundra Vegetation in the 1990s: Comparison of Two NDVI Datasets from NOAA AVHRR Systems. International Journal of Remote Sensing, 28, 4807-4822. https://doi.org/10.1080/01431160701264284 
Submit or recommend next manuscript to SCIRP and we will provide best service for you:

Accepting pre-submission inquiries through Email, Facebook, LinkedIn, Twitter, etc. A wide selection of journals (inclusive of 9 subjects, more than 200 journals)

Providing 24-hour high-quality service

User-friendly online submission system

Fair and swift peer-review system

Efficient typesetting and proofreading procedure

Display of the result of downloads and visits, as well as the number of cited articles Maximum dissemination of your research work

Submit your manuscript at: http://papersubmission.scirp.org/

Or contact jgis@scirp.org 